\title{
Erratum: Design Thinking Research
}

\section{Hasso Plattner}

Hasso Plattner Institute for Software Systems Engineering

Potsdam, Germany

hasso.plattner@hpi.unipotsdam.de

\section{Christoph Meinel}

Hasso Plattner Institute for Software Systems Engineering

Potsdam, Germany

christoph.meinel@hpi.unipotsdam.de

\section{Larry Leifer}

Stanford University

Stanford, CA, USA

leifer@cdr.stanford.edu

(C) Springer International Publishing Switzerland 2016

H. Plattner et al. (eds.), Design Thinking Research, Understanding Innovation

DOI 10.1007/978-3-319-40382-3_18

Errata to:

Chapter 6: On Creating Workspaces for a Team of Teams: Learnings from a Case Study, doi: 10.1007/978-3-319-40382-3_6

Marie Klooker, Claudia Nicolai, Stephan Matzdorf, Arne Trost, Karen von Schmieden, Lilith Böttcher and Ulrich Weinberg

Chapter 16: The Topic Markup Scheme and the Knowledge Handling Notation: Complementary Instruments to Measure Knowledge Creation in Design Conversations, doi: 10.1007/978-3-319-40382-3_16

Axel Menning, Andrea Scheer, Claudia Nicolai and Ulrich Weinberg 
In the original version for these papers, the name of the author Ulrich Weinberg was omitted.

The updated original online version for these chapters can be found at http://dx.doi.org/10.1007/978-3-319-40382-3_6

http://dx.doi.org/10.1007/978-3-319-40382-3_16 